alternative energy sources and dual-chamber leadless pacing in the not-too-distant future. Although effective, current electronic devices have limitations related to lead or generator malfunction, lack of autonomic responsiveness, undesirable interactions with strong magnetic fields, and device-related infections. Biological pacemakers, generated by somatic gene transfer, cell fusion, or cell transplantation, provide an alternative to electronic devices. Somatic reprogramming strategies, which involve transfer of genes encoding transcription factors to transform working myocardium into a surrogate sinoatrial node, are furthest along in the translational pipeline. Even as electronic pacemakers become smaller and less invasive, biological pacemakers might expand the therapeutic armamentarium for conduction system disorders.

Humans can be born alive without many of the major organs, but the heart is indispensable for the embryo to progress beyond 10 weeks of gestation ${ }^{1}$. Even with an anatomically normal heart, an insufficient rate of contraction is highly lethal: untreated congenital heart block portends a fetal mortality of $\sim 80 \%^{2}$. In postnatal life, cessation of the heartbeat results in circulatory collapse and sudden death. Thus, pacemakers have understandably revolutionized the practice of cardiology. Implantable pacemakers set the pace of the heartbeat when the endogenous rate drops excessively. Despite their demonstrated efficacy, conventional electronic pacemakers have a number of limitations, most notably associated with lead malfunction, finite battery life, and device-related infections. In this Review, we discuss next-generation electronic devices designed to address current limitations, as well as biological pacemakers as alternatives to implantable hardware.

\section{Cardiac conduction system}

\section{Normal cardiac conduction system}

A healthy heart beats $>3$ billion times in a typical lifetime owing to the remarkable capacity of the endogenous pacemaker to produce rhythmic, spontaneous electrical impulses. The cardiac conduction system then spreads the impulse throughout the heart, exciting the upper (atrial) and lower (ventricular) cardiac pumping chambers in a coordinated manner ${ }^{3,4}$, appropriately responsive to modulation by the autonomic nervous system ${ }^{5}$ (FIG. 1).

The main pacemaker of the heart resides in the sinus node, also known as the sinoatrial node (SAN), located at the junction of the superior vena cava and right atrium ${ }^{6,7}$. Electrical impulses originate in the SAN, travel rapidly across the right and left atrial muscle to initiate atrial contraction, and then slow when encountering the atrioventricular (AV) node (FIG. 1a). The AV node delay allows the atria to contract and prime the ventricles with blood for their subsequent contraction. The AV node is also a secondary pacemaker that can serve as a backup (albeit at a much slower rate) in the event of primary SAN failure ${ }^{6,7}$. After the AV node, the electrical impulse proceeds along the His bundle, the only electrical connection between the atria and the ventricles ${ }^{6,7}$, and then rapidly spreads throughout the ventricles via a network of specialized Purkinje fibres, which make contact with the working cardiomyocytes $^{6,7}$. Cells from the different areas of the conduction system have characteristic complements of ion channels and gap junctions that generate different action potential profiles (FIG. 1b), allowing each tissue to function in a specific manner. 
During embryonic development, as early as embryonic day 7.5 (E7.5) in mice, the cells of the primitive heart tube beat spontaneously, with most of the automaticity originating in cells from the precardiac mesoderm located in the inflow tract region ${ }^{8}$. In mice, these cells reside in the sinus venosus and express potassium/ sodium hyperpolarization-activated cyclic nucleotidegated channel 4 (HCN4) and the transcription factor homeobox protein NKX2.5 (REF. 9). A series of transcription factors including insulin gene enhancer protein ISL1, short stature homeobox protein 2 (SHOX2), and the T-box transcription factors TBX3 and TBX5 activate the SAN gene programme in the sinus venosus (FIG. 1c), whereas NKX2.5, TBX3, and TBX18 repress the chamber myocyte gene programme in the sinus venosus, the AV canal, and the inner curvature, thereby allowing pacemaking cells to dominate in these regions ${ }^{9}$. Re-expression of transcription factors such as SHOX2 and TBX18 in postnatal mouse ventricular cardiomyocytes has been used to transform chamber cardiomyocytes into pacemaker cells that possess all the main characteristics of SAN cells ${ }^{10,12}$; this finding is the basis for a strategy to create biological pacemakers, as discussed below. By the time looping occurs at E9.5, the conduction system activation pattern in the heart tube follows that of the adult heart ${ }^{9,13}$.

SAN cells have dual oscillators to provide stable rhythmic diastolic depolarization for triggering pacemaker action potentials. These two oscillators are referred to as the 'membrane clock' and the 'calcium clock' (REF 14) (FIG. 2). The membrane clock oscillator is in the plasma membrane and relies on the pacemaker current - or funny current $\left(I_{\mathrm{f}}\right)^{15}$ - which is generated through HCN4. The generated inward current causes diastolic depolarization and subsequent activation of T-type and L-type calcium channel currents ( $I_{\mathrm{CaL}}$; which in the SAN is generated predominantly by the $\mathrm{Ca}_{\mathrm{v}} 1.3$ calcium channel ${ }^{16}$ ). Depolarization mediated by the inward calcium current $\left(I_{\mathrm{Ca}}\right)$ provides the characteristic slow depolarization of the SAN action potential compared with chamber cardiomyocytes, which rely on the inward sodium current - generated by the sodium channel $\mathrm{Na}_{\mathrm{v}} 1.5$ - for the action potential rapid upstroke phase. The membrane clock works in concert with the internally driven calcium clock ${ }^{17,18}$. In this second oscillator, diastolic depolarization is facilitated by rhythmic release of calcium from the sarcoplasmic reticulum and consequent depolarization by the electrogenic sodium-calcium exchanger $(\mathrm{NCX})^{19,20}$. The inward current carried by $I_{\mathrm{f}}$ and $\mathrm{NCX}$ acting synergistically suffices to depolarize the surface membrane to the threshold of activation of $I_{\mathrm{Ca}}$. Although sodium currents do not have a major role in SAN pacemaker activity, these currents do facilitate conduction out of the SAN and into the surrounding atrial tissue.

$I_{\mathrm{f}}$ can be modulated by the autonomic nervous system through adrenergic and muscarinic stimulation, as well as by drugs such as ivabradine that alter the pacemaker rate by influencing the slope of diastolic depolarization ${ }^{21}$. Autonomic receptor stimulation modulates the activity of cAMP-dependent protein kinase (PKA) and calcium/calmodulindependent protein kinase type II (CAMKII), which in turn influence both the membrane clock and calcium clock by regulating the phosphorylation of hyperpolarization-activated cyclic nucleotide-gated $(\mathrm{HCN})$ channels, calcium channels, ryanodine receptors, and other proteins that regulate sarcoplasmic reticulum refilling and release of calcium ${ }^{22}$. Elevations in intracellular calcium increase calcium-dependent phosphorylation, whereas phosphodiesterases, when active, counteract the effects of phosphorylation ${ }^{23,24}$. 
Although other parts of the conduction system (AV node, His bundle, bundle branches, and Purkinje fibres) can fire spontaneously, they do so at a slower rate than that of the SAN and usually at rates insufficient to support the circulation. Therefore, the SAN sets the heart rate by overriding the slower pacemakers below it. If spontaneous pacing below the SAN were faster, such ectopic pacemakers would compete with the SAN and could potentially cause arrhythmias.

\section{Conduction system disease}

Pacemaker and/or conduction system disturbances can result from a failure in impulse generation by the SAN or from a block of impulse propagation at any point in the conduction system. Other causes of conduction failure, which we do not describe here, include abnormal pathways of conduction owing to developmental accidents.

The most common identifiable causes of conduction block arise from physical destruction of part of the conduction system; for example, valvular infections owing to endocarditis can form abscesses that compress or erode the AV node. Likewise, implantation of a prosthetic valve can impinge the adjacent conduction system, leading to reversible or irreversible heart block $^{25}$. In rare cases, congenital, complete heart block develops in response to circulating factors (possibly antibodies that impede AV conduction) transferred from the mother to the fetus ${ }^{26}$. Nevertheless, the most common cause of conduction disturbance is progressive cardiac conduction disease (or Lev-Lenegre disease) ${ }^{27}$, an idiopathic, age-related condition characterized by fibrosis of the conduction system. Regardless of the aetiology, treatment of these irreversible conditions is determined primarily by the presence of associated symptoms (such as fatigue, dizziness, or fainting) and the degree of heart-rate slowing ${ }^{28}$.

\section{Electronic pacemakers}

\section{Evolution of device technology}

Electronic pacemakers are the mainstay of therapy for slow heart rhythms (bradycardia) owing to cardiac conduction system disease ${ }^{28}$. Every year, $>200,000$ patients undergo permanent pacemaker implantation to treat these conditions in the USA alone ${ }^{29}$. The first successful applications of electrotherapy in patients with bradycardia involved external pulse generators connected to the chest wall or directly to the heart via wires ${ }^{30}$. For obvious reasons, mobility was limited, and the devices were uncomfortable. In 1958, the first fully implantable pacemaker was placed by open thoracotomy at the Karolinska Institute, Sweden (FIG. 3). The device, designed by Rune Elmqvist and Ake Senning, had epicardial electrodes that connected directly to the heart ${ }^{31}$; the pacemaker supported the patient's heart rhythm for $3 \mathrm{~h}$ and then had to be replaced by a new device. This patient required a total of 26 pacemaker changes throughout his lifetime, dying aged 86 years from an unrelated cause $^{32}$. In the USA, implantable electronic pacemakers designed and built by Wilson Greatbatch using mercury-based battery technology were introduced for human use in the $1960 \mathrm{~s}^{33}$. The first patient implanted with the Greatbatch pacemaker lived for 18 months.

Since the first implantable electronic pacemakers were developed 6 decades ago, we have witnessed continuous improvements in device technology, with advances in lead design, 
generator size, battery longevity, and software algorithms that have resulted in smaller devices with improved functionality (FIG. 3). One of the main limitations of early electronic devices was the extremely short battery lifespan. In an attempt to solve this issue, multiple companies developed nuclear-powered pacemakers ${ }^{34,35}$. The first isotope-based pacemaker $\left({ }^{238} \mathrm{Pu}\right)$ was implanted in April 1970 in France ${ }^{34}$. Such isotope-based devices were capable of producing stable pacing for $>30$ years to provide fixed or asynchronous pacing ${ }^{34}$. Later generations of isotope-based pacemakers had synchronous pacing capabilities, which allowed for sensing of the intrinsic patient rhythm and then pacing only on demand when no underlying intrinsic rhythm was present. Despite their extraordinary battery longevity, these devices were replaced by next-generation devices with lithium-based battery technology and improved software algorithms ${ }^{34,36}$. Given the obvious safety concerns of isotope-powered devices, lithium-based batteries quickly became the standard source of power for modern electronic pacemakers ${ }^{37}$.

\section{Modern device technologies}

Implantable electronic pacemaker technology has continued to evolve, and we now have a variety of technologically advanced devices capable of providing reliable pacing for different patient populations ${ }^{28}$. Today's modern devices can sense the intrinsic rhythm in both the atrium and ventricle and can pace either chamber on demand at a programmable baseline heart rate. Although current lithium-based battery technologies can provide stable pacing for $\sim 10$ years, battery longevity can be extended further by software algorithms. Algorithms that iteratively test the minimum output required (pacing threshold) to capture the myocardium (autocapture) can automatically adjust the output, increasing the longevity of the pacemaker to $>10$ years ${ }^{38,39}$. Additionally, modern software algorithms can monitor for the presence of $\mathrm{AV}$ nodal conduction and minimize right ventricular (RV) pacing in those patients with intermittent $\mathrm{AV}$ nodal block ${ }^{40,41}$. The goal is to avoid (when possible) the potential deleterious effects of chronic RV pacing, such as electrical and mechanical dyssynchrony and RV pacing-induced cardiomyopathy ${ }^{42,43}$. An additional pacing modality to treat RV pacing-induced cardiomyopathy, which also revolutionized the management of heart failure (HF), is cardiac resynchronization therapy (CRT), also known as biventricular pacing ${ }^{44}$. Biventricular pacing, achieved by placing a left ventricular (LV) lead through a coronary venous branch in addition to a conventional RV lead, has been proven to prolong survival and improve symptoms and LV ejection fraction (EF) in patients with HF with widened QRS complexes (corresponding to ventricular depolarization) on the electrocardiogram (ECG) ${ }^{44-46}$. Given that approximately one-third of patients do not show improvements in functional capacity or EF with CRT, novel, multipoint pacing modalities have been developed ${ }^{47}$ to pace the left ventricle at multiple points ${ }^{48}$. Randomized clinical trials to compare the effects of bipolar versus quadripolar leads in patients with CRT are ongoing 44 .

The capacity to capture the His-Purkinje network by placing a pacing electrode in the His bundle region has given rise to an additional pacing modality, His bundle pacing ${ }^{49}$. This modality creates fast antegrade (forward) activation of the ventricles, with the consequent narrow QRS complex on surface ECG ${ }^{44,50}$. Interestingly, His-Purkinje recruitment by His bundle pacing occurs not only in patients with AV block at the level of the AV node, but also 
in patients with $\mathrm{AV}$ block below the $\mathrm{AV}$ node (infranodal block) ${ }^{50}$. Although larger studies are needed to understand better the long-term benefits of this modality, His-bundle pacing might be a superior alternative to apical RV pacing ${ }^{44}$.

Electronic pacemakers with a subcutaneous generator connected to endovascular pacing lead(s) can provide different pacing modalities: single-chamber, dual-chamber, biventricular, and His-bundle pacing ${ }^{44,51}$. Additionally, some modern devices have software algorithms that detect and treat atrial tachyarrhythmias by overdrive-pacing the atria and interrupting the arrhythmia circuit ${ }^{52}$.

Although effective, these devices do entail substantial risks; complications are often related to either lead insertion or malfunction ${ }^{53}$ or to infections of the leads and/or generators ${ }^{44,54,55}$. Such infections can be life-threatening and generally require removal of all hardware, during which time temporary pacing strategies are required ${ }^{56}$. Additionally, leads can be thrombogenic, creating upper extremity deep venous thrombosis ${ }^{57}$. Leads can also affect tricuspid valve leaflet motion, causing clinically significant tricuspid regurgitation ${ }^{58}$.

Given the potential of lead-related complications, leadless pacemakers have been developed ${ }^{59}$. In such devices, the pulse generator, the battery, and the sensing and pacing electrodes are self-contained in a small capsule designed to be delivered into the right ventricle through a steerable sheath inserted through the femoral vein ${ }^{60,61}$. The major limitations of current leadless pacemakers are the need for a large-bore (18-24 French) venous delivery system, the uncertainty about infectious and thrombogenic risks, and their capacity to provide only single-chamber RV pacing ${ }^{44}$. Single-chamber pacing prevents the use of leadless pacemakers for common indications for cardiac pacing such as sick sinus syndrome, where atrial pacing is preferred, or in conditions where AV synchrony is desired, such as sinus rhythm with chronic AV block ${ }^{28}$.

\section{Next-generation devices}

As discussed above, current-generation pacemakers have limitations related to lead(s) or generator malfunction, thrombosis, infections, and lack of a physiological autonomic response. Additionally, pacemaker implantation in children has additional challenges owing to the smaller body size, rapid growth, and long life-expectancy of children and the anatomical variations associated with congenital heart defects ${ }^{62}$. In general, epicardial pacing (with leads placed via thoracotomy) is recommended for patients with $<15 \mathrm{~kg}$ of body weight and/or unfavourable anatomy (for example, presence of an intracardiac shunt or a single ventricle). However, epicardial pacing leads are more prone to fracture and often need to be replaced by either a new epicardial lead or an endocardial system when possible ${ }^{62,63}$.

With contemporary battery technologies, generators need to be replaced every $\sim 10$ years (depending on pacemaker utilization), requiring multiple generator changes, with the associated cumulative risk of procedure-related complications. Alternative energy sources, such as conformal piezoelectric energy harvesting ${ }^{64,65}$ and solar-powered pacemakers ${ }^{66}$, are currently being studied at preclinical stages. Conformal piezoelectric energy harvesting 
technology, long-used in wristwatches, uses the movements of internal organs such as heart, lung, and diaphragm to enable mechanical-to-electrical energy conversion ${ }^{64,65}$. By contrast, solar-powered devices utilize a subcutaneous solar module to convert transcutaneous light into the electrical energy required for self-sustainable cardiac pacing ${ }^{66}$. Additional preclinical testing is required to assess the reliability and duration of these self-sustained power technologies.

To solve lead-related complications as well as infections associated with subcutaneous (extravascular) generators, leadless pacemakers have some promise ${ }^{59-61}$. Although leadless pacemakers have been used in patients with device-related infections ${ }^{67}$, the risk of bacteraemic 'seeding' of the leadless device remains to be studied in the long term. Additionally, current-generation leadless pacemakers can provide only single-chamber RV pacing ${ }^{44}$. With advances in wireless communication technologies, we foresee the development of next-generation, dual leadless pacemakers capable of sensing and/or pacing in both cardiac chambers, resulting in sequential $\mathrm{AV}$ pacing ${ }^{68}$.

Although device manufacturers have developed different sensing systems and software algorithms to provide rate adaptation, current-generation pacemakers do not have true autonomic responsiveness to satisfy physiological needs. Impedance measurements from the pacing electrode have been used to estimate myocardial contractile performance (as a surrogate of sympathetic activation) ${ }^{69}$. More commonly, most electronic pacemakers have a programmable accelerometer to detect patient activity and adjust pacing rate in response to exercise $^{70,71}$. Although these systems are designed to satisfy physiological demands, given the complexity of the autonomic innervation of the cardiac conduction system ${ }^{5}$, it is difficult to conceive that device-based technologies will be able accurately to reproduce physiological rate responses. Nevertheless, with ongoing advancements in sensors and wearable technologies, next-generation pacemakers are likely to combine different sensing systems (that is, accelerometer, impedance, cardiac output, and blood pressure) and complex software algorithms to support more accurately the physiological needs.

\section{Biological pacemakers}

Despite continuous improvements in device technologies, electronic pacemakers still have limitations and complications ${ }^{55,72-75}$. Several situations warrant non-device options. Patients with hardware-related infections who require a pacemaker have a contraindication to reimplantation before effective antibiosis is established. In at least one instance (congenital heart block), life-threatening bradycardia cannot be treated by electronic pacemakers. This condition results in fetal death or stillbirth in $\sim 80 \%$ of cases and would necessitate in utero pacing ${ }^{76,77}$, which is not yet feasible. Consequently, biological pacemakers are being developed to provide a therapeutic alternative to electronic devices.

\section{Proof-of-concept studies}

Different biological approaches to enhance cardiac automaticity have been investigated over the years (FIG. 4). The common goal is to generate an ectopic region of automaticity in the heart that can function as a surrogate for the SAN. Various gene-based and cell-based approaches to generate biological pacemakers have been described ${ }^{72}$. 
Gene-based approaches.-The earliest 'genes-only' approach to increase automaticity involved overexpression of the genes encoding the human $\beta_{2}$-adrenergic receptors in mouse $^{78}$ and porcine ${ }^{79}$ atria. Although this approach did not generate a biological pacemaker, endogenous SAN rate was accelerated by increasing the number of $\beta_{2^{-}}$ adrenergic receptors available for binding to endogenous catecholamines ${ }^{78,79}$.

The first de novo biological pacemaker was created by gene therapy and reported in 2002 (REF 80). The strategy was to release the 'electrical brake' that suppresses automaticity in ventricular cardiomyocytes by inhibiting the endogenous inward rectifier potassium current $\left(7_{\mathrm{K} 1}\right)$. Miake et al. reduced the number of functional inward rectifier potassium ion channels (encoded by the KIR2 gene family; also known as $K C N J 2$ ) in the myocardium by overexpressing a KIR2.1 -dominant-negative construct (KIR2.1AAA) in guinea pig hearts ${ }^{80}$ (FIG. 4a). This suppression of $I_{\mathrm{K} 1}$ released the intrinsic capacity of ventricular cardiomyocytes to depolarize spontaneously, thereby generating biological pacemaker activity ${ }^{80}$. Notably, the strategy was not designed to create a genuine phenocopy of the SAN; instead, this technique was a 'functional engineering' approach whereby manipulation of a single ionic current unleashed biological pacemaker activity in ventricular cardio-myocytes that otherwise remained structurally and genetically unaltered. Follow-up studies demonstrated that KIR2.1AAA overexpression not only affected the resting membrane potential (generating spontaneous depolarizations), but also led to prolongation of action potential duration when KIR2.1AAA was less-intensely expressed in the heart ${ }^{81}$. Although diffuse suppression of $I_{\mathrm{K} 1}$ in ventricular myocardium can predispose to arrhythmias ${ }^{72}$, as seen clinically in familial long QT syndrome type 7 (REF 82), the potential pro-arrhythmic effects of focal suppression of $\mathrm{I}_{\mathrm{K} 1}$ (as required for generating biological pacemaker activity) were not characterized in these proof-of-concept, small-animal studies ${ }^{80,81}$. Given this important consideration, every biological therapy that has the potential to increase cardiac automaticity (regardless of changes in action potential duration) should be carefully characterized in several preclinical models (including large animals with slow heart rates, like that of humans) to rule out potential pro-arrhythmic effects (see next section).

In the SAN, $I_{\mathrm{f}}$ has an important role in cardiac pacemaking ${ }^{83}$. An additional functional reengineering (gene-based) approach, first reported by Qu et al. in a canine model, involved the overexpression of $\mathrm{Hcn} 2$ to elicit biological pacemaker activity ${ }^{84}$. Adenoviral constructs with mouse $\mathrm{Hcn} 2$ were delivered by open thoracotomy to the root of the left atrial appendage; 4 days after the injection, the anaesthetized dogs had spontaneous rhythms that originated from the left atria after suppressing sinus rhythm by vagal stimulation ${ }^{84}$. Followup studies from the same group demonstrated that injection of Hcn2-expressing adenovirus into the left bundle branch resulted in spontaneous ventricular rhythms after vagal stimulation ${ }^{85}$. Taken together, these independent, proof-of-concept studies demonstrated the capacity to create biological pacemaker activity by functional re-engineering by either suppressing $\mathrm{I}_{\mathrm{K} 1}$ (releasing the intrinsic beating capacity of cardiomyocytes) or by expressing $\mathrm{I}_{\mathrm{f}}$ channels in normal working cardiomyocytes ${ }^{80,84,85}$.

Cell-based approaches.-In cell-based approaches, a cluster of spontaneously beating cells is transplanted into the heart to elicit ectopic biological pacemaker activity ${ }^{72,86}$ (FIG. 4b). The earliest attempt utilized fetal cardiomyocytes injected in the hearts of two dogs with 
iatrogenic AV block with a resultant ventricular escape rhythm not observed in two control $\operatorname{dog} 8{ }^{87}$. The cell transplantation approach has been sporadically mimicked since then with various spontaneously beating cell types.

Human embryonic stem cells (hESCs) readily differentiate into spontaneously beating cardiomyocytes $^{88}$. In vivo transplantation of hESC-derived cardiomyocytes into guinea pigs resulted in biological pacemaker activity confirmed by ex vivo optical mapping ${ }^{89}$. After AV nodal ablation, those animals that had previously been injected with hESC-derived cardiomyocytes exhibited spontaneous biological pacemaker activity originating at the injection site (demonstrated by optical mapping). Given the human origin of these cells, immunosuppression was required to prevent rejection ${ }^{90}$.

SAN-like cardiomyocytes derived from human induced pluripotent stem cells (iPSCs) have been used to create biological pacemaker activity in vitro and in vivo (REF 91). In another study from an independent group, iPSC-derived cardiomyocytes were delivered into dog hearts by open thoracotomy ${ }^{92}$. Biological pacemaker activity was seen in only $50 \%$ of the animals, with beating rates of 40-50 bpm (REF. 92). Although attractive, iPSC-derived biological pacemakers face substantial hurdles for clinical translation: current iPSC technologies produce a mixed population of cells with various phenotypes. This issue not only affects the function of iPSC-derived biological pacemakers (as previously reported ${ }^{92}$ ), but is also a safety concern given the potential of immature cells to migrate or to differentiate into different cell types (such as teratomas). Moreover, generating iPSCs requires weeks to months; any given patient would have to defer implantation until their autologous cardiomyocytes became available, which limits the potential patient candidates to those not requiring urgent chronotropic support.

Hybrid gene-cell approaches.-One combined or hybrid approach has been the delivery of cells carrying pacemaker genes (for example, genes encoding $\mathrm{HCN}$ channels) into the heart to generate biological pacemaker activity (FIG. 4c). Human mesenchymal stem cells (hMSCs) engineered to express the pacemaker channel HCN2 were delivered by open thoracotomy in dogs with complete AV block ${ }^{93}$. Animals injected with engineered HCN2-expressing hMSCs showed biological pacemaker activity with ventricular rates of $50-60 \mathrm{bpm}$ and no evidence of cellular or humoral rejection ${ }^{93}$. Potential advantages of this approach include avoiding a viral vector (used in most gene therapy approaches) and immunosuppression (given the low immunogenicity of hMSCs). Although the absence of rejection without immunosuppression is an important advantage of this approach, the fairly low heart rates achieved and concerns about potential migration and further differentiation of hMSCs are important limitations of this strategy ${ }^{75,94}$.

Another hybrid approach used engineered syngeneic fibroblasts expressing $\mathrm{HCN} 1$ injected into guinea pig hearts in a vehicle designed to induce cell fusion with surrounding endogenous ventricular cells ${ }^{95}$. The study documented the formation of fibroblast-myocyte heterokaryons and biological pacemaker activity originating at the injection site ${ }^{95}$. Although this alternative represents a non-viral, non-stem-cell approach to biological pacemakers, additional preclinical studies with optimized, minimally invasive delivery systems are needed if translational efforts for cell-fusion biological pacemakers are to proceed. 
Somatic reprogramming approaches.-Starting in 2013, a conceptually different alternative has been developed with a view to clinical translation. Unlike functional reengineering approaches, which transferred either mutant ${ }^{80}$ or wild-type ion channel genes ${ }^{96}$ to generate biological pacemaker activity, transfer of genes encoding transcription factors has the potential to create faithful replicas of genuine pacemaker cells. This 'somatic reprogramming' approach has been applied in practice by overexpressing the gene coding for the human embryonic transcription factor TBX18 in ventricular cardiomyocytes ${ }^{11}$ (FIG. 4d). Transfer of $T B X 18$ induced the conversion of cardiomyocytes into induced SAN (iSAN) cells that resembled endogenous SAN pacemaker cells ${ }^{11}$. With this approach, no single determinant of excitability is selectively overexpressed; instead, the entire geneexpression programme is altered, with resultant changes in fundamental cell physiology and morphology ${ }^{55,97}$. Initial studies demonstrated that TBX18-induced reprogramming created electrical automaticity by both voltage clock and calcium clock mechanisms ${ }^{11}$ (FIG. 2). Interestingly, iSAN cells had many of the phenotypic and functional characteristics of native SAN cells ${ }^{11}$ (FIG. 5). Moreover, in vivo somatic reprogramming by TBX18 created a biological pacemaker rhythm in guinea pig hearts that not only originated from the injection site, but also responded to catecholamines ${ }^{11}$. As described below, this somatic reprogramming technology has been advanced into a large-animal model of complete heart block $^{98}$.

\section{Large-animal studies}

To develop a biological pacemaker candidate ready for clinical testing, addressing the following considerations is important: delivery system, preferred biological agent, and target patient population. The most notable large-animal studies are summarized in TABLE 1 . The studies differ in the choice of animal model (swine versus canine), the duration of follow-up, and, most importantly, the assessment of efficacy and safety. Most studies used repeated ECGs and/or serial Holter recordings to assess biological pacemaker activity and potential pro-arrhythmic effects, but only one study used real-time, continuous ECG telemetry to characterize biological pacemaker activity and cardiac safety (check for arrhythmias) ${ }^{98}$. Although short-term biological pacemakers have been successfully generated in largeanimal models by gene-based, cell-based, and reprogramming-based therapies, the delivery

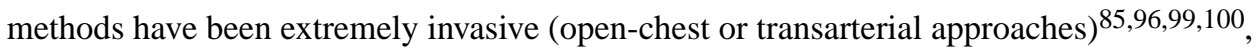
limiting the potential for human translation. Gene-based biological pacemakers have been successfully delivered by catheter-based techniques, but cell-based biological pacemakers have yet to be delivered by minimally invasive (catheter) techniques. As described in the previous section, cell-based biological pacemakers rely on successful transplantation and engraftment of a cluster of spontaneously beating cells capable of electrically entraining the surrounding myocardium. A critical mass of clustered beating cells (derived from hESCs or iPSCs) is required to capture the heart successfully and create biological pacemaker activity. Given the limitations of open-chest and transarterial approaches, we have developed a rightsided (venous) delivery approach in a swine model of complete heart block ${ }^{101}$ whereby biological pacemaker vectors can be delivered percutaneously through a catheter placed in the femoral vein. 
To date, studies on ion channel-based (functional re-engineering) biological pacemakers have used recombinant adenovirus as the gene delivery vector. Adenoviral vectors have been used in $>40$ human clinical trials (completed) as an alternative to standard therapies in different disease conditions. Additionally, various clinical trials of adenoviral gene therapy in patients with different cardiac diseases are currently in the recruitment phase. One limitation of the use of adenoviral vectors is their temporary nature: transduced cells express the transgene robustly for several weeks, but the cells are then cleared by the immune system ${ }^{102,103}$. However, given the generally favourable safety profile in human clinical trials, the lack of genomic integration, and the proven safety and efficacy in preclinical studies, adenoviral vectors remain a viable option for certain clinical applications (see next section).

After the initial proof-of-concept studies showing somatic reprogramming by TBX18 both in vitro and in vivo ${ }^{11}$, Hu et al. delivered $T B X 18$ by a minimally invasive technique in a swine model of complete heart block ${ }^{98}$. Adenovirus carrying $T B X 18$ was delivered to the His-bundle region by a single venous catheter (introduced through an 8 French venous sheath) without the need for thoracotomy or arterial access. Animals were monitored by implanted, continuous ECG telemetry, and activity was measured by a built-in accelerometer. TBX18-treated animals had stable biological pacemaker activity originating at the injection site (as demonstrated by in vivo electroanatomical mapping) and improved exercise capacity. Moreover, no signs of local (proarrhythmic) or systemic adverse effects occurred during follow-up ${ }^{98}$. The reprogramming-based strategy, by transforming adult cardiac cells into iSAN cells, might be a more physiologically-based biological pacemaker than previously described, ion channel-based strategies.

In summary, large-animal studies performed in two clinically relevant models (swine and canine) using either open thoracotomy or catheter-based delivery systems have shown the feasibility and safety of biological pacing. The most robust preclinical data come from genebased and reprogramming-based approaches.

\section{Ideal population for first-in-human-trial}

Although biological pacemakers might supplant electronic pacemakers in the future, we should be realistic about potential first-in-human applications. If effective and safe, a biological pacemaker can be extremely valuable in the following conditions: device-related infections, chronic atrial fibrillation (AF) with slow ventricular response, and congenital (intrauterine) AV block.

Device-related infections.-Device-related infections have been increasing in the past decade as a result of not only the increase in pacemaker implantations but also the higher incidence of bacterial infections worldwide and the substantial associated morbidity and mortality ${ }^{104,105}$. The presence of an indwelling foreign body such as a pacemaker device predisposes a patient to life-threatening infections of the leads and/or the generator ${ }^{106,107}$. Patients with device-related infections generally require complete removal of all hardware until they become infection-free on systemic antibiotics ${ }^{54}$. For those patients who depend on the pacemaker, a temporary transvenous pacing device needs to be utilized during the 
antibiotic treatment, which typically requires $\sim 2$ weeks. Moreover, the presence of an indwelling catheter can potentially undermine the capacity of systemic antibiotics to clear the infection. Device-related infections are independent markers of long-term mortality and are costly ${ }^{105,107}$. A hardware-free, temporary pacing alternative would be desirable in such patients to support the circulation in the interval after removal of the infected hardware and before implantation of a new, definitive permanent electronic pacemaker. An effective biological pacemaker could potentially provide temporary pacing, eliminating the need for indwelling hardware during antibiotic therapy and improving the outcomes and effectiveness of such therapy by removing any possible nidus of infection associated with temporary, transvenous leads.

Chronic atrial fibrillation.-Chronic AF associated with AV nodal disease can present with slow ventricular response and symptoms such as fatigue, dizziness, and syncope. These patients do not require AV synchrony (like in persistent AF); therefore, these patients are often treated with either single-chamber pacemakers or, more recently, leadless pacemakers. Biological pacemakers delivered by a minimally invasive delivery system could, in principle, be a viable, hardware-free alternative to single-chamber pacing or could decrease battery utilization (by diminishing pacemaker utilization) in those patients with a previously implanted pacemaker.

Congenital AV block.-Congenital AV block, when severe, can result in hydrops fetalis, stillbirth, and postpartum circulatory collapse. This disease is more common in mothers with systemic lupus erythematosus, and severe forms of this disorder do not respond to conventional therapies (systemic steroids). Moreover, electronic devices cannot be implanted in utero or in newborn babies. If safely delivered, a biological pacemaker could (in principle) be the only available therapy for congenital AV block.

Before the first-in-human biological pacemaker clinical trial, performing long-term efficacy and safety studies using a clinically realistic animal model with the proposed biological candidate is critical. Being able to deliver the biological pacemaker product through a minimally invasive delivery system is an obvious advantage. Additionally, efficacy and safety studies need to be replicated with the use of vectors (or cells) generated under good manufacturing practice conditions. Formal toxicology and biodistribution studies need to be performed according to the standards of regulatory agencies, such as the FDA.

\section{Timeline for biological pacemakers}

Predicting how long it might take for the biological pacemakers to reach the clinic and thereafter have a substantial effect on clinical practice is difficult. The time course of the development of the implantable cardioverter-defibrillator (ICD) serves as a helpful benchmark (TABLE 2). The initial concept, which occurred in the mid-1960s to cardiologist Michel Mirowski, was first reported in 1970 (REF 108). The idea was considered audacious and subjected to ridicule by establishment cardiologists ${ }^{109}$. The first clinical application of the ICD was reported 10 years later. Patient selection was restricted to those with recurrent cardiac arrest episodes despite receiving conventional therapy, and implantation was performed by open thoracotomy ${ }^{110}$. The device turned out to be highly efficacious. Over the 
next 3 decades, implantation of the ICD became entirely percutaneous, and the ICD is now part of routine care for those patients at general risk of fatal arrhythmias; indeed, ICDs are implanted prophylactically in hundreds of thousands of patients annually ${ }^{111}$. With the biological pacemaker, we remain at the preclinical stage. As with the ICD, the technology has been ridiculed by an establishment cardiologist ${ }^{112}$. Only time will tell whether the biological pacemaker will succeed in clinical translation and, if so, how major the effect will be in clinical practice.

\section{Conclusions}

Conduction system disorders are currently treated with electronic pacemakers. Electronic pacemaker technologies continue to evolve, and latest-generation devices are smaller, have longer battery duration, and improved functionality compared with previous devices. In the future, we will probably see further improvements in electronic devices: progressive miniaturization; dual-chamber, leadless pacing; and improved sensor technologies to better adjust to metabolic and physiological needs. Different electronic pacemakers are currently available to treat specific patient populations (such as single-chamber or leadless devices in chronic AF or biventricular pacemakers in HF with wide QRS complex), and device technologies will probably have further improvements tailored to specialized patient needs. If successfully tested in niche populations (for example, patients with device-related infections), biological pacemakers might provide a therapeutic alternative to devices in the future management of patients with conduction system disorders.

\section{Acknowledgements}

The authors' work on biological pacemakers in funded by the US NIH RO1 HL135866 and NIH RO1 HL048509.

\section{References}

1. Miranda JO, Ramalho C, Henriques-Coelho T \& Areias JC Fetal programming as a predictor of adult health or disease: the need to reevaluate fetal heart function. Heart Fail. Rev. 22, 861-877 (2017). [PubMed: 28730459]

2. Friedman D, Duncanson L, Glickstein J \& Buyon J A review of congenital heart block. Images Paediatr. Cardiol. 5, 36-48 (2003). [PubMed: 22368629]

3. Marban E Cardiac channelopathies. Nature 415, 213-218 (2002). [PubMed: 11805845]

4. Bers DM Cardiac excitation-contraction coupling. Nature 415, 198-205 (2002). [PubMed: 11805843]

5. Crick SJ et al. Innervation of the human cardiac conduction system. A quantitative immunohistochemical and histochemical study. Circulation 89, 1697-1708 (1994). [PubMed: 7908612]

6. Anderson RH, Yanni J, Boyett MR, Chandler NJ \& Dobrzynski H The anatomy of the cardiac conduction system. Clin. Anat. 22, 99-113 (2009). [PubMed: 18773472]

7. Anderson RH \& Ho SY The architecture of the sinus node, the atrioventricular conduction axis, and the internodal atrial myocardium. J. Cardiovasc. Electrophysiol. 9, 1233-1248 (1998). [PubMed: 9835269]

8. Epstein JA Franklin H. Epstein Lecture. Cardiac development and implications for heart disease. $N$. Engl. J. Med. 363, 1638-1647 (2010). [PubMed: 20961247]

9. van Weerd JH \& Christoffels VM The formation and function of the cardiac conduction system. Development 143, 197-210 (2016). [PubMed: 26786210] 
10. Ionta $\mathrm{V}$ et al. SHOX2 overexpression favors differentiation of embryonic stem cells into cardiac pacemaker cells, improving biological pacing ability. Stem Cell Rep. 4, 129-142 (2015).

11. Kapoor N, Liang W, Marban E \& Cho HC Direct conversion of quiescent cardiomyocytes to pacemaker cells by expression of Tbx18. Nat. Biotechnol. 31, 54-62 (2013). [PubMed: 23242162]

12. Liang W, Cho HC \& Marban E Wnt signalling suppresses voltage-dependent Na+ channel expression in postnatal rat cardiomyocytes. J. Physiol. 593, 1147-1157 (2015). [PubMed: 25545365]

13. Christoffels VM \& Moorman A F Development of the cardiac conduction system: why are some regions of the heart more arrhythmogenic than others? Circul. Arrhythmia Electrophysiol 2, 195207 (2009).

14. Eisner DA \& Cerbai E Beating to time: calcium clocks, voltage clocks, and cardiac pacemaker activity. Am. J. Physiol. Heart Circ. Physiol. 296, H561-H562 (2009). [PubMed: 19151259]

15. DiFrancesco D Characterization of single pacemaker channels in cardiac sino-atrial node cells. Nature 324, 470-473 (1986). [PubMed: 2431323]

16. Mangoni ME et al. Functional role of L-type Cav1.3 $\mathrm{Ca}^{2+}$ channels in cardiac pacemaker activity. Proc. Natl Acad. Sci. USA 100, 5543-5548 (2003). [PubMed: 12700358]

17. Huser $\mathrm{J}$ et al. Functional coupling between glycolysis and excitation-contraction coupling underlies alternans in cat heart cells. J. Physiol. 524, 795-806 (2000). [PubMed: 10790159]

18. Bogdanov KY, Vinogradova TM \& Lakatta EG Sinoatrial nodal cell ryanodine receptor and Na+$\mathrm{Ca} 2$ + exchanger: molecular partners in pacemaker regulation. Circul. Res 88, 1254-1258 (2001).

19. Groenke $\mathrm{S}$ et al. Complete atrial-specific knockout of sodium-calcium exchange eliminates sinoatrial node pacemaker activity. PloS ONE 8, e81633 (2013). [PubMed: 24278453]

20. Torrente AG et al. Burst pacemaker activity of the sinoatrial node in sodium-calcium exchanger knockout mice. Proc. Natl Acad. Sci. USA 112, 9769-9774 (2015). [PubMed: 26195795]

21. DiFrancesco D \& Borer JS The funny current: cellular basis for the control of heart rate. Drugs 67 (Suppl. 2), 15-24 (2007). [PubMed: 17999560]

22. Walsh KB \& Kass RS Regulation of a heart potassium channel by protein kinase A and C. Science 242, 67-69 (1988). [PubMed: 2845575]

23. Monfredi O, Maltsev VA \& Lakatta EG Modern concepts concerning the origin of the heartbeat. Physiology 28, 74-92 (2013). [PubMed: 23455768]

24. Vinogradova TM et al. High basal protein kinase A-dependent phosphorylation drives rhythmic internal $\mathrm{Ca} 2+$ store oscillations and spontaneous beating of cardiac pacemaker cells. Circul. Res. 98, 505-514 (2006).

25. Bleiziffer $\mathrm{S}$ et al. Predictors for new-onset complete heart block after transcatheter aortic valve implantation. JACC Cardiovasc. Interv. 3, 524-530 (2010). [PubMed: 20488409]

26. Izmirly PM. et al. Clinical and pathologic implications of extending the spectrum of maternal autoantibodies reactive with ribonucleoproteins associated with cutaneous and now cardiac neonatal lupus from SSA/Ro and SSB/La to U1RNP. Autoimmun. Rev 16, 980-983 (2017). [PubMed: 28709760]

27. Ramos S, Matturri L, Rossi L \& Rossi M Scleroatrophy of the atrioventricular junctional specialized tissue (Lenegre-Lev Disease) in chronic chagas' heart disease. Acta Cardiol. 50, 483487 (1995). [PubMed: 8932569]

28. Epstein AE et al. 2012 ACCF/AHA/HRS focused update incorporated into the ACCF/AHA/HRS 2008 guidelines for device-based therapy of cardiac rhythm abnormalities: a report of the American College of Cardiology Foundation/American Heart Association Task Force on Practice Guidelines and the Heart Rhythm Society. J. Am. Coll. Cardiol. 61, e6-e75 (2013). [PubMed: 23265327]

29. Greenspon AJ et al. Trends in permanent pacemaker implantation in the United States from 1993 to 2009: increasing complexity of patients and procedures. J. Am. Coll. Cardiol. 60, 1540-1545 (2012). [PubMed: 22999727]

30. Aquilina O A brief history of cardiac pacing. Images Paediatr. Cardiol. 8, 17-81 (2006). [PubMed: 22368662]

31. van Hemel NM \& van der Wall EE 8 October 1958, D Day for the implantable pacemaker. Neth. Heart J 16 (Suppl. 1), S3-S4 (2008). [PubMed: 18958267] 
32. Larsson B, Elmqvist H, Rydén L \& Schüller H Lessons from the first patient with an implanted pacemaker: 1958-2001. Pacing Clin. Electrophysiol. 26, 114-124 (2003). [PubMed: 12685152]

33. Chardack WM, Gage AA \& Greatbatch W A transistorized, self-contained, implantable pacemaker for the long-term correction of complete heart block. Surgery 48, 643-654 (1960). [PubMed: 13692461]

34. Parsonnet V, Driller J, Cook D \& Rizvi SA Thirty-one years of clinical experience with "nuclearpowered" pacemakers. Pacing Clin. Electrophysiol. 29, 195-200 (2006). [PubMed: 16492308]

35. Smyth NP, Keshishian JD, Garcia JM, Kelly LC \& Proctor D Clinical experience with the isotopic cardiac pacemaker. Ann. Thorac. Surg. 28, 14-21 (1979). [PubMed: 454038]

36. Burr LH The lithium iodide-powered cardiac pacemaker. Clinical experience with 250 implantations. J. Thorac. Cardiovasc. Surg. 73, 421-423 (1977). [PubMed: 839832]

37. Mond HG \& Freitag G The cardiac implantable electronic device power source: evolution and revolution. Pacing Clin. Electrophysiol. 37, 1728-1745 (2014). [PubMed: 25387600]

38. Boriani G et al. Role of ventricular Autocapture function in increasing longevity of DDDR pacemakers: a prospective study. Europace 8, 216-220 (2006). [PubMed: 16627443]

39. Biffi M et al. Actual pacemaker longevity: the benefit of stimulation by automatic capture verification. Pacing Clin. Electrophysiol. 33, 873-881 (2010). [PubMed: 20230462]

40. Milasinovic $\mathrm{G}$ et al. Percent ventricular pacing with managed ventricular pacing mode in standard pacemaker population. Europace 10, 151-155 (2008). [PubMed: 18203737]

41. Gillis AM et al. Reducing unnecessary right ventricular pacing with the managed ventricular pacing mode in patients with sinus node disease and AV block. Pacing Clin. Electrophysiol. 29, 697-705 (2006). [PubMed: 16884504]

42. Saito $\mathrm{M}$ et al. Effect of right ventricular pacing on right ventricular mechanics and tricuspid regurgitation in patients with high-grade atrioventricular block and sinus rhythm (from the protection of left ventricular function during right ventricular pacing study). Am. J. Cardiol. 116, 1875-1882 (2015). [PubMed: 26517949]

43. Ahmed FZ et al. One-month global longitudinal strain identifies patients who will develop pacinginduced left ventricular dysfunction over time: the Pacing and Ventricular Dysfunction (PAVD) Study. PloS ONE 12, e0162072 (2017). [PubMed: 28095413]

44. Madhavan M, Mulpuru SK, McLeod CJ, Cha YM \& Friedman PA Advances and future directions in cardiac pacemakers: part 2 of a 2-part series. J. Am. Coll. Cardiol. 69, 211-235 (2017). [PubMed: 28081830]

45. Moss AJ et al. Cardiac-resynchronization therapy for the prevention of heart-failure events. $N$. Engl. J. Med. 361, 1329-1338 (2009). [PubMed: 19723701]

46. Bristow MR et al. Cardiac-resynchronization therapy with or without an implantable defibrillator in advanced chronic heart failure. N. Engl. J. Med. 350, 2140-2150 (2004). [PubMed: 15152059]

47. Leclercq $\mathrm{C}$ et al. A randomized comparison of triplesite versus dual-site ventricular stimulation in patients with congestive heart failure. J. Am. Coll. Cardiol. 51, 1455-1462 (2008). [PubMed: 18402900]

48. Turakhia MP et al. Reduced mortality associated with quadripolar compared to bipolar left ventricular leads in cardiac resynchronization therapy. JACC Clin. Electrophysiol. 2, 426-433 (2016). [PubMed: 29759861]

49. Mulpuru SK, Cha YM \& Asirvatham SJ Synchronous ventricular pacing with direct capture of the atrioventricular conduction system: functional anatomy, terminology, and challenges. Heart Rhythm 13, 2237-2246 (2016). [PubMed: 27498079]

50. Vijayaraman P, Dandamudi G, Worsnick S \& Ellenbogen KA Acute His-bundle injury current during permanent His-bundle pacing predicts excellent pacing outcomes. Pacing Clin. Electrophysiol. 38, 540-546 (2015). [PubMed: 25588497]

51. Mulpuru SK, Madhavan M, McLeod CJ, Cha YM \& Friedman PA Cardiac pacemakers: function, troubleshooting, and management: part 1 of a 2-part series. J. Am. Coll. Cardiol. 69, 189-210 (2017). [PubMed: 28081829]

52. Boriani G \& Padeletti L Management of atrial fibrillation in bradyarrhythmias. Nat. Rev. Cardiol. 12, 337-349 (2015). [PubMed: 25781413] 
53. Hauser RG et al. Clinical experience with pacemaker pulse generators and transvenous leads: an 8year prospective multicenter study. Heart Rhythm 4, 154-160 (2007). [PubMed: 17275749]

54. Sohail MR et al. Management and outcome of permanent pacemaker and implantable cardioverterdefibrillator infections. J. Am. Coll. Cardiol. 49, 1851-1859 (2007). [PubMed: 17481444]

55. Cingolani E \& Marbán E Recreating the sinus node by somatic reprogramming: a dream come true? Rev. Esp. Cardiol. 68, 743-745 (2015). [PubMed: 26183662]

56. Baddour LM et al. Update on cardiovascular implantable electronic device infections and their management: a scientific statement from the American Heart Association. Circulation 121, 458477 (2010). [PubMed: 20048212]

57. Basar $\mathrm{N}$ et al. Upper-extremity deep vein thrombosis and downhill esophageal varices caused by long-term pacemaker implantation. Tex. Heart Inst. J. 37, 714-716 (2010). [PubMed: 21224954]

58. Delling FN et al. Tricuspid regurgitation and mortality in patients with transvenous permanent pacemaker leads. Am. J. Cardiol. 117, 988-992 (2016). [PubMed: 26833208]

59. Miller MA, Neuzil P, Dukkipati SR \& Reddy VY Leadless cardiac pacemakers: back to the future. J. Am. Coll. Cardiol. 66, 1179-1189 (2015). [PubMed: 26337997]

60. Reddy VY et al. Permanent leadless cardiac pacing: results of the LEADLESS trial. Circulation 129, 1466-1471 (2014). [PubMed: 24664277]

61. Piccini JP et al. Long-term outcomes in leadless Micra transcatheter pacemakers with elevated thresholds at implantation: results from the Micra Transcatheter Pacing System Global Clinical Trial. Hear: Rhythm 14, 685-691 (2017).

62. Singh HR, Batra AS \& Balaji S Pacing in children. Ann. Pediatr. Cardiol. 6, 46-51 (2013). [PubMed: 23626436]

63. Fortescue EB et al. Patient, procedural, and hardware factors associated with pacemaker lead failures in pediatrics and congenital heart disease. Hear: Rhythm 1, 150-159 (2004).

64. Dagdeviren $\mathrm{C}$ et al. Conformal piezoelectric systems for clinical and experimental characterization of soft tissue biomechanics. Nat. Mater. 14, 728-736 (2015). [PubMed: 25985458]

65. Dagdeviren $\mathrm{C}$ et al. Conformal piezoelectric energy harvesting and storage from motions of the heart, lung, and diaphragm. Proc. Natl Acad. Sci. USA 111, 1927-1932 (2014). [PubMed: 24449853]

66. Haeberlin A et al. The first batteryless, solar-powered cardiac pacemaker. Heart Rhythm 12, 13171323 (2015). [PubMed: 25744612]

67. Kypta A et al. Leadless cardiac pacemaker implantation after lead extraction in patients with severe device infection. J. Cardiovasc. Electrophysiol. 27, 1067-1071 2016). [PubMed: 27296508]

68. Bornzin GA et al. Dual-chamber leadless intracardiac medical device with intra-cardiac extension. U.S. Patent 8634912 (2014).

69. Schaldach M \& Hutten H Intracardiac impedance to determine sympathetic activity in rate responsive pacing. Pacing Clin. Electrophysiol. 15, 1778-1786 (1992). [PubMed: 1279547]

70. Ellenbogen KA, Kay GN \& Wilkoff BL Clinical Cardiac Pacing (W. B. Saunders Company, 1995).

71. Lloyd $\mathrm{M}$ et al. Rate adaptive pacing in an intracardiac pacemaker. Heart Rhythm 14, 200-205 (2017). [PubMed: 27871854]

72. Cho HC \& Marbán E Biological therapies for cardiac arrhythmias: can genes and cells replace drugs and devices? Circul. Res. 106, 674-685 (2010).

73. Rosen MR Gene therapy and biological pacing. N. Engl. J. Med. 371, 1158-1159 (2014). [PubMed: 25229921]

74. Rosen MR, Robinson RB, Brink PR \& Cohen IS. The road to biological pacing. Nature reviews. Cardiology 8, 656-666 (2011). [PubMed: 21844918]

75. Cingolani E Biological pacemakers: Ready for the clinic? Trends Cardiovasc. Med 25, 674-675 (2015). [PubMed: 25850979]

76. Gutierrez M et al. Maternal connective tissue disease associated with congenital AV block [Spanish]. Rev. Med. Chil. 117, 789-793 (1989). [PubMed: 2519435]

77. Scott JS \& Taylor PV Congenital AV-block: role of anti-Ro and anti-La antibodies. Springer Semin. Immunopathol. 11, 397-408 (1989). [PubMed: 2694407] 
78. Edelberg JM, Aird WC \& Rosenberg RD Enhancement of murine cardiac chronotropy by the molecular transfer of the human $\beta 2$ adrenergic receptor cDNA. J. Clin. Invest. 101, 337-343 (1998). [PubMed: 9435305]

79. Edelberg JM, Huang DT, Josephson ME \& Rosenberg RD Molecular enhancement of porcine cardiac chronotropy. Heart 86, 559-562 (2001). [PubMed: 11602553]

80. Miake J, Marban E \& Nuss HB Biological pacemaker created by gene transfer. Nature 419, 132 133 (2002).

81. Miake J, Marban E \& Nuss HB Functional role of inward rectifier current in heart probed by Kir2.1 overexpression and dominant-negative suppression. J. Clin. Invest. 111, 1529-1536 (2003). [PubMed: 12750402]

82. Tristani-Firouzi M et al. Functional and clinical characterization of $K C N J 2$ mutations associated with LQT7 (Andersen syndrome). J. Clin. Invest. 110, 381-388 (2002). [PubMed: 12163457]

83. Baruscotti M, Bucchi A \& Difrancesco D Physiology and pharmacology of the cardiac pacemaker ("funny") current. Pharmacol. Ther. 107, 59-79 (2005). [PubMed: 15963351]

84. Qu J et al. Expression and function of a biological pacemaker in canine heart. Circulation 107, 1106-1109 (2003). [PubMed: 12615786]

85. Plotnikov AN et al. Biological pacemaker implanted in canine left bundle branch provides ventricular escape rhythms that have physiologically acceptable rates. Circulation 109, 506-512 (2004). [PubMed: 14734518]

86. Rosen MR, Brink PR, Cohen IS \& Robinson RB Genes, stem cells and biological pacemakers. Cardiovasc. Res. 64, 12-23 (2004). [PubMed: 15364609]

87. Ruhparwar A et al. Transplanted fetal cardiomyocytes as cardiac pacemaker. Eur. J. Cardiothorac. Surg. 21, 853-857 (2002). [PubMed: 12062274]

88. Xu C, Police S, Rao N \& Carpenter MK Characterization and enrichment of cardiomyocytes derived from human embryonic stem cells. Circul. Res 91, 501-508 (2002).

89. Xue $\mathrm{T}$ et al. Functional integration of electrically active cardiac derivatives from genetically engineered human embryonic stem cells with quiescent recipient ventricular cardiomyocytes: insights into the development of cell-based pacemakers. Circulation 111, 11-20 (2005). [PubMed: 15611367]

90. Kehat I et al. Electromechanical integration of cardiomyocytes derived from human embryonic stem cells. Nat. Biotechnol. 22, 1282-1289 (2004). [PubMed: 15448703]

91. Protze SI et al. Sinoatrial node cardiomyocytes derived from human pluripotent cells function as a biological pacemaker. Nat. Biotechnol. 35, 56-68 (2017). [PubMed: 27941801]

92. Chauveau $\mathrm{S}$ et al. Induced pluripotent stem cell-derived cardiomyocytes provide in vivo biological pacemaker function. Circul. Arrhythmia Electrophysiol. 10, e004508 (2017).

93. Plotnikov AN et al. Xenografted adult human mesenchymal stem cells provide a platform for sustained biological pacemaker function in canine heart. Circulation 116, 706-713 (2007). [PubMed: 17646577]

94. Liechty KW et al. Human mesenchymal stem cells engraft and demonstrate site-specific differentiation after in utero transplantation in sheep. Nat. Med. 6, 1282-1286 (2000). [PubMed: 11062543]

95. Cho HC, Kashiwakura Y \& Marban E Creation of a biological pacemaker by cell fusion. Circuí. Res. 100, 1112-1115 (2007).

96. Bucchi A et aí. Wild-type and mutant HCN channels in a tandem biological-electronic cardiac pacemaker. Circulation 114, 992-999 (2006). [PubMed: 16923750]

97. Marban E \& Cingolani E Direct reprogramming: bypassing stem cells for therapeutics. JAMA 314, 19-20 (2015). [PubMed: 26151260]

98. Hu YF, Dawkins JF, Cho HC, Marban E \& Cingolani E Biological pacemaker created by minimally invasive somatic reprogramming in pigs with complete heart block. Sci. Transí Med 6, 245-94 (2014).

99. Potapova I et al. Human mesenchymal stem cells as a gene delivery system to create cardiac pacemakers. Circuí. Res 94, 952-959 (2004). 
100. Tse HF et al. Bioartificial sinus node constructed via in vivo gene transfer of an engineered pacemaker HCN Channel reduces the dependence on electronic pacemaker in a sick-sinus syndrome model. Circuíation 114, 1000-1011 (2006).

101. Cingolani $\mathrm{E}$ et al. Biological pacemaker created by percutaneous gene delivery via venous catheters in a porcine model of complete heart block. Heart Rhythm 9, 1310-1318 (2012). [PubMed: 22521937]

102. Liu Q et aí. The role of capsid-endothelial interactions in the innate immune response to adenovirus vectors. Hum. Gene Ther 14, 627-643 (2003). [PubMed: 12804145]

103. Muruve DA The innate immune response to adenovirus vectors. Hum. Gene Ther 15, 1157-1166 (2004). [PubMed: 15684693]

104. Chua JD et al. Diagnosis and management of infections involving implantable electrophysiologic cardiac devices. Ann. Intern. Med 133, 604-608 (2000). [PubMed: 11033588]

105. Cabell $\mathrm{CH}$ et al. Increasing rates of cardiac device infections among Medicare beneficiaries: 1990-1999. Am. Hear: J. 147, 582-586 (2004).

106. Athan E et al. Clinical characteristics and outcome of infective endocarditis involving implantable cardiac devices. JAMA 307, 1727-1735 (2012). [PubMed: 22535857]

107. Sohail MR, Henrikson CA, Braid-Forbes MJ, Forbes KF \& Lerner DJ Mortality and cost associated with cardiovascular implantable electronic device infections. Arch. Intern. Med 171, 1821-1828 (2011). [PubMed: 21911623]

108. Mirowski M, Mower MM, Staewen WS, Tabatznik B \& Mendeloff AI Standby automatic defibrillator. An approach to prevention of sudden coronary death. Arch. Intern. Med 126, 158161 (1970). [PubMed: 5425512]

109. Lown B \& Axelrod P Implanted standby defibrillators. Circuíation 46, 637-639 (1972).

110. Mirowski $\mathrm{M}$ et al. Termination of malignant ventricular arrhythmias with an implanted automatic defibrillator in human beings. N. Engí. J. Med 303, 322-324 (1980).

111. Mond HG \& Proclemer A The 11th world survey of cardiac pacing and implantable cardioverterdefibrillators: calendar year 2009 - a World Society of Arrhythmia's project. Pacing Cíin. Eíectrophysió́ 34, 1013-1027 (2011).

112. Bolli R Dandum semper est tempus: the crucial importance of (and increasing disregard for) the test of time. Circuí. Res 117, 755-757 (2015).

113. Plotnikov AN et al. HCN212-channel biological pacemakers manifesting ventricular tachyarrhythmias are responsive to treatment with $\mathrm{I}_{\mathrm{f}}$ blockade. Hear:Rhythm 2, 282-288 (2008).

114. Shlapakova IN et al. Biological pacemakers in canines exhibit positive chronotropic response to emotional arousal. Heart Rhythm 12, 1835-1840 (2010).

115. Boink GJ et al. HCN2/SkMI gene transfer into canine left bundle branch induces stable, autonomically responsive biological pacing at physiological heart rates. J. Am. Coíi. Cardiol. 61, 1192-1201 (2013).

Nat Rev Cardiol. Author manuscript; available in PMC 2018 November 28. 


\section{Key points}

- The heartbeat originates from spontaneous depolarizations in the sinoatrial node, which lead to the spread of electrical signals throughout the heart via a specialized conduction system

- $\quad$ Failure of the sinoatrial node pacemaker or disease of the conduction system results in slow heart rates that can cause fainting or sudden death

- $\quad$ Current therapies rely on electronic pacemakers to provide an adequate heart rate to satisfy haemodynamic needs

- $\quad$ Electronic pacemaker technologies continue to evolve; however, electronic pacemakers have limitations including battery life, system failure, inability to provide true autonomic response, and device-related infections

- Biological pacemakers, currently at the preclinical stage, might be an alternative to electronic devices for selected patients in the future 


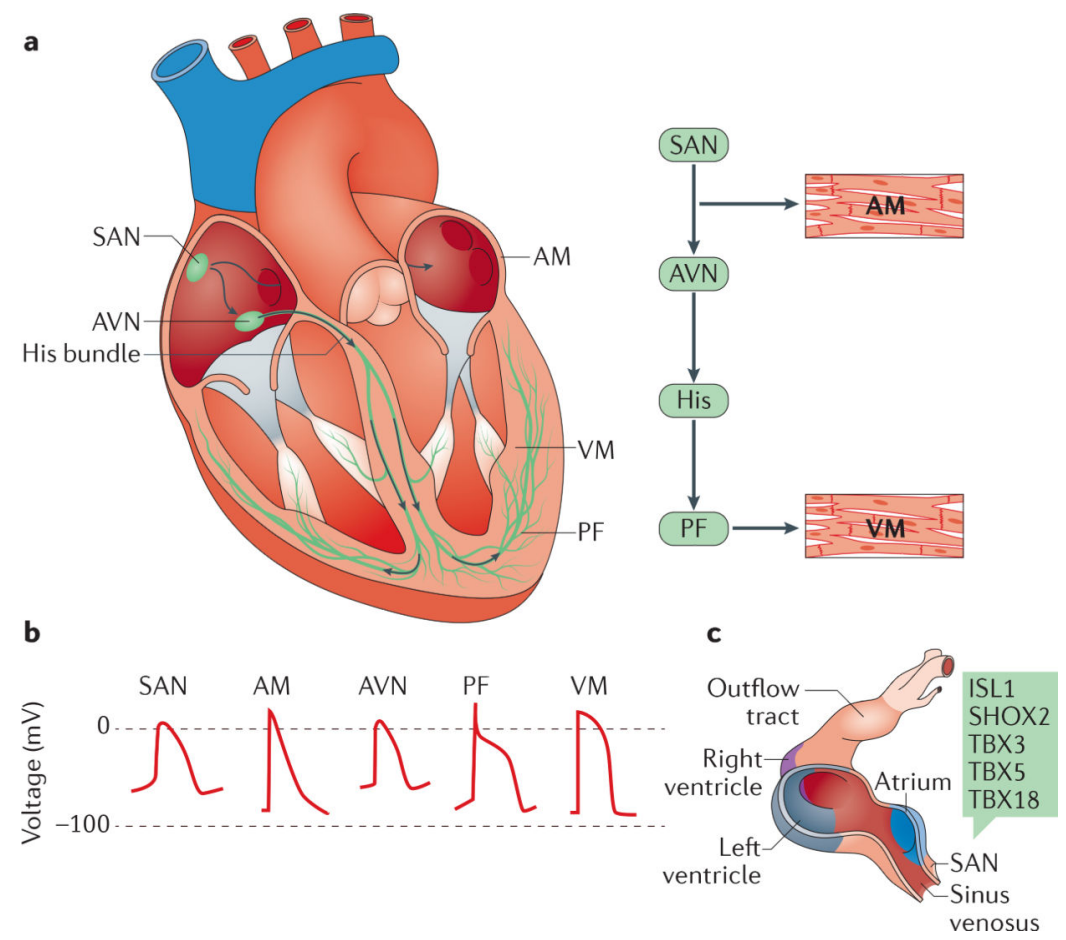

Figure 1 |. Cardiac conduction system.

a) Schematic representation of the anatomy and cellular electrophysiology of the cardiac conduction system. The cardiac impulse (arrows) originates in the sinoatrial node (SAN), travels across the atrial myocardium (AM), and moves through the atrioventricular node $(\mathrm{AVN})$, the His bundle, and left and right bundle branches. The simultaneous activation of both bundle branches and their terminal Purkinje fibres (PF) provides antegrade activation of the ventricular myocardium (VM) in a synchronized fashion. $\mathbf{b} \mid$ Distinct action potential morphologies at different levels of the conduction system impose specialized electrical behaviours. c| Development of the SAN in mice. The SAN forms in the sinus venosus; during early embryonic development of the heart, transcription factors (green box) activate the SAN gene programme in the sinus venosus, while repressing the chamber myocyte gene programme. Chamber myocardium is depicted in purple, grey, and blue; non-chamber myocardium in dark pink; and non-myocardial tissue in light pink. ISL1, insulin gene enhancer protein ISL1; SHOX2, short stature homeobox protein 2; TBX, T-box transcription factor. Part c adapted from REF 9. http://creativecommons.org/licenses/by/3.0/. 


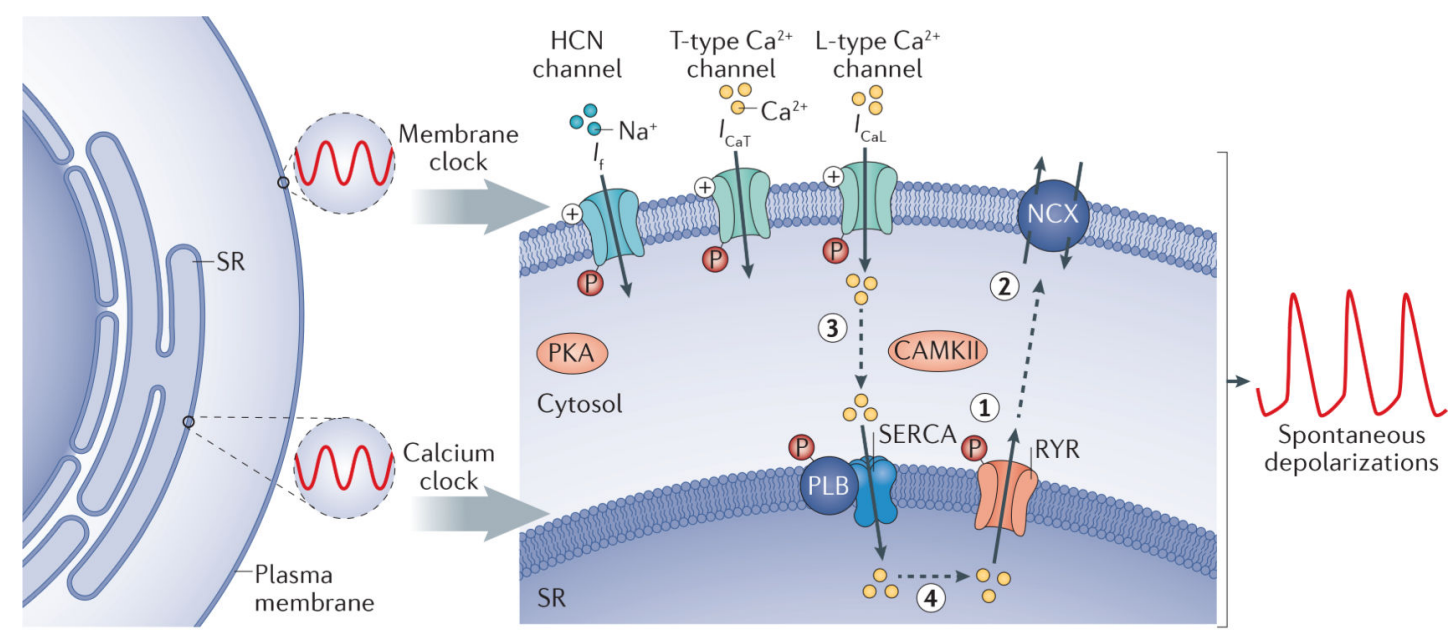

Figure 2 |. Mechanisms of sinoatrial node automaticity.

A dual oscillator system consisting of a membrane clock and a calcium clock provides stable rhythmic depolarizations. The membrane clock relies on the pacemaker current (via hyperpolarization-activated cyclic nucleotide-gated (HCN) channels), L-type calcium channels, and T-type calcium channels for diastolic depolarization. The calcium clock works in synchrony with the membrane clock by releasing calcium from the sarcoplasmic reticulum (SR) through ryanodine receptors (RYRs) (step 1), thereby depolarizing the cell in diastole by activating the sodium-calcium exchanger (NCX) (step 2). The sarcoplasmic/ endoplasmic reticulum calcium ATPase (SERCA), modulated by cardiac phospholamban (PLB), moves the calcium entering through the calcium channels in the plasma membrane back into the SR (step 3) to prime the calcium for the next cycle (step 4). Both the membrane clock and the calcium clock act in synchrony to create spontaneous depolarizations and are regulated by the autonomic nervous system through $\beta$-adrenergic and muscarinic stimulation, which modulates the activity of protein kinases (cAMPdependent protein kinase (PKA) and calcium/calmodulin-dependent protein kinase type II (CAMKII)) that phosphorylate multiple proteins in the system. The calcium cycle is represented by the dashed grey arrows. $I_{\mathrm{CaL}}$, L-type calcium channel current; $I_{\mathrm{CaT}}$, T-type calcium channel current; $I_{\mathrm{f}}$, funny current. 


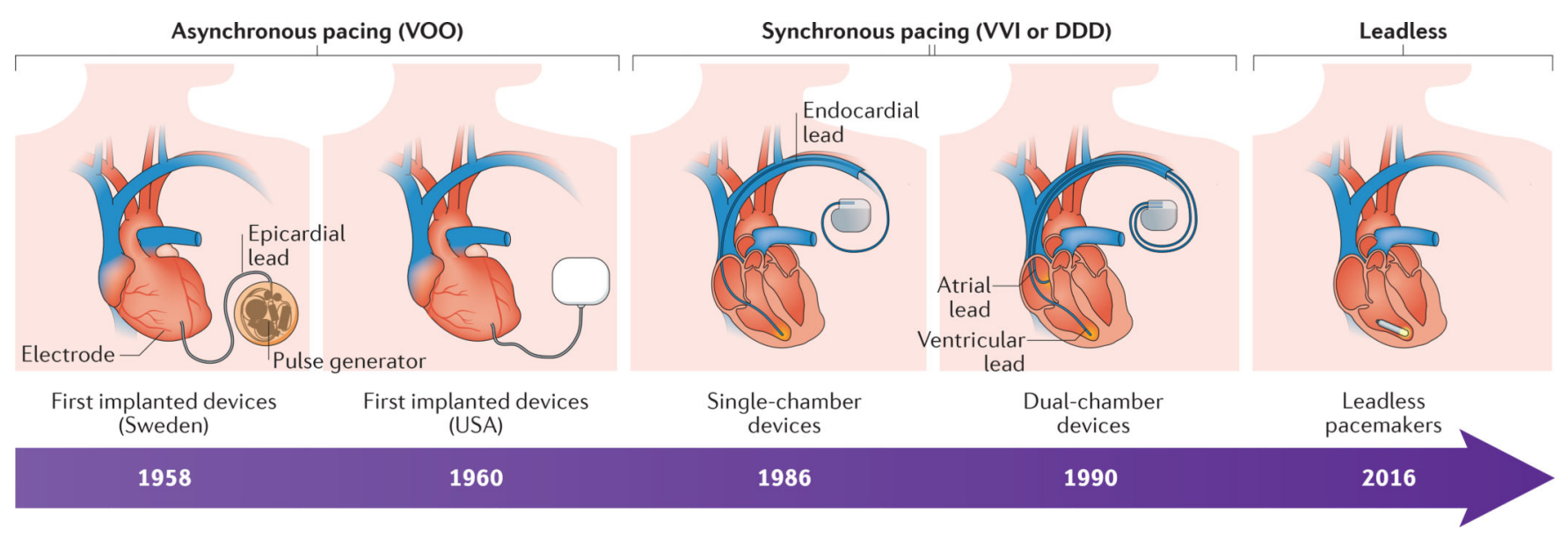

Figure 3 |. Timeline of the evolution of electronic pacemakers.

Early electronic pacemaker devices were big, had epicardial leads, and were implanted by open thoracotomy. Modern devices (single-chamber devices and dual-chamber devices) are much smaller, use endocardial leads, and can be implanted with minimally invasive techniques. First-generation devices provided only asynchronous (VOO) pacing, whereas modern devices are capable of synchronous and/or on-demand (VVI/DDD) pacing. Leadless pacemakers have a self-contained capsule that includes the battery, generator, and pacing electrodes, and are implanted percutaneously through the femoral vein. 

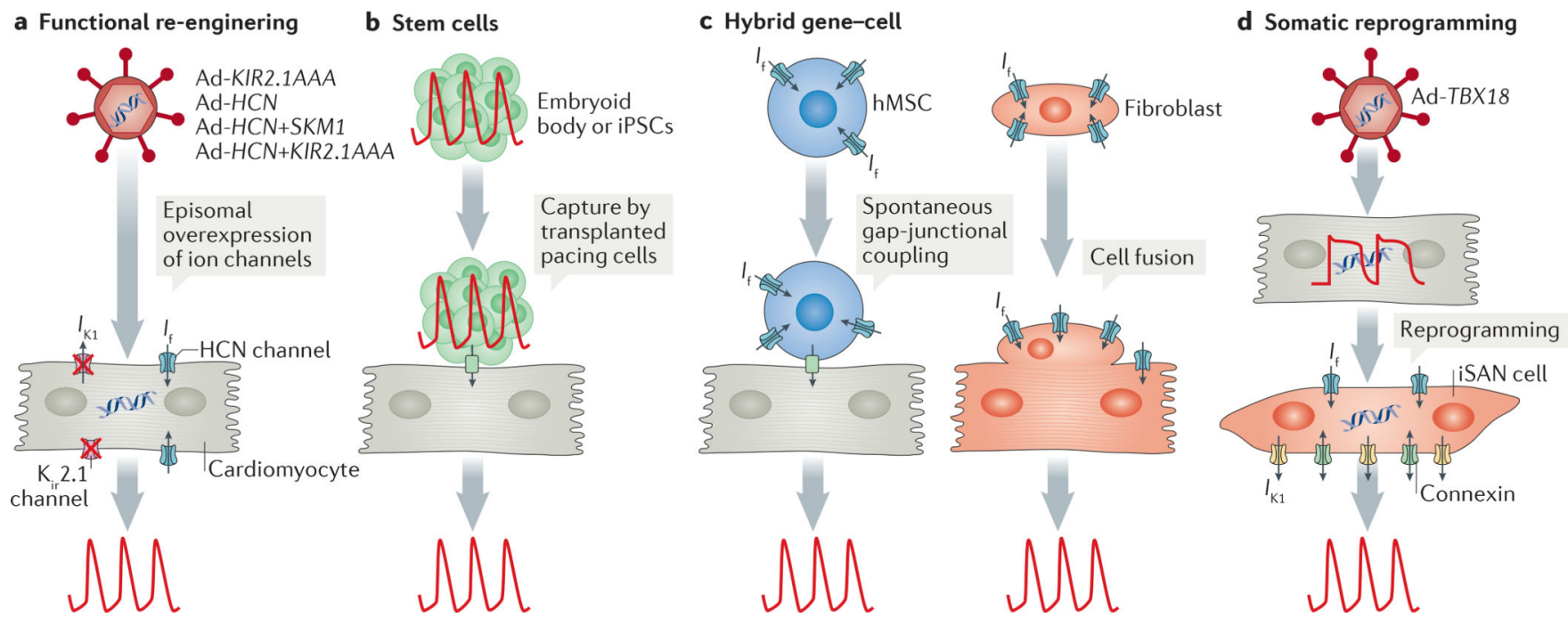

Figure 4 |. Biological pacemaker approaches.

a In a functional re-engineering approach, adenoviral (Ad) vectors are used to overexpress genes encoding ion channels (single channel or a combination of channels) in cardiomyocytes to create automaticity, for example, to increase the number of hyperpolarization-activated cyclic nucleotidegated $(\mathrm{HCN})$ channels and to reduce the number of functional inward-rectifier potassium channels $\left(\mathrm{K}_{\mathrm{ir}} 2.1\right)$ by overexpressing a dominant negative construct (KIR2.1AAA). b | With a stem cell approach, a cluster of beating cells derived from human embryonic stem cells (called an embryoid body) or induced pluripotent stem cells (iPSCs) are transplanted into a specific location in the heart to capture surrounding myocardium, thereby creating biological pacing. $\mathbf{c} \mid$ In a hybrid approach, cells (human mesenchymal stem cells (hMSCs) or fibroblasts) are used to deliver ion channel genes (for example, genes encoding components of $\mathrm{HCN}$ channels) to produce cardiac automaticity. Delivery by hMSCs requires gap-junctional coupling between the cardiomyocyte and the hMSC, whereas delivery by fibroblasts involves cell fusion. $\mathbf{d} \mid$ In somatic reprogramming, overexpression of the T-box transcription factor TBX18 by use of Ad vectors reprogrammes adult cardiac chamber cardiomyocytes into induced sinoatrial node (iSAN) cells, recapitulating the features of the SAN and therefore creating pacemaker activity. $\mathrm{I}_{\mathrm{f}}$, funny current; $\mathrm{I}_{\mathrm{K} 1}$, inward rectifier current. 
a

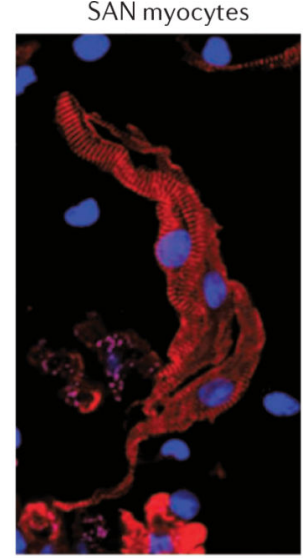

$\alpha-\mathrm{SA}$ -DAPI
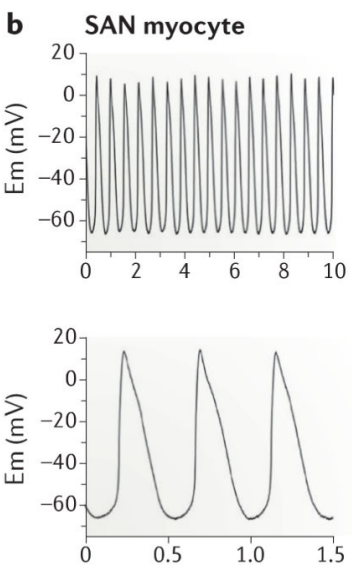

TBX18-VM

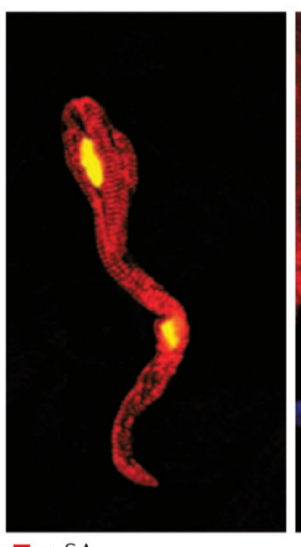

$\alpha-\mathrm{SA}$

TBX18

TBX18-VM
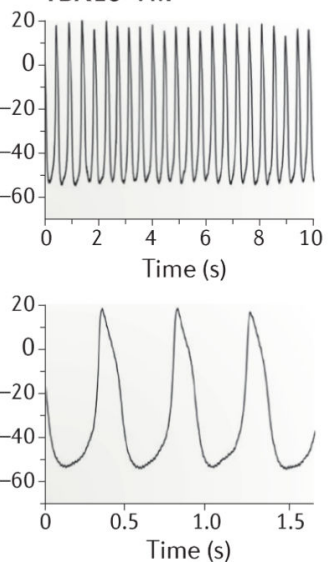

GFP-VMs
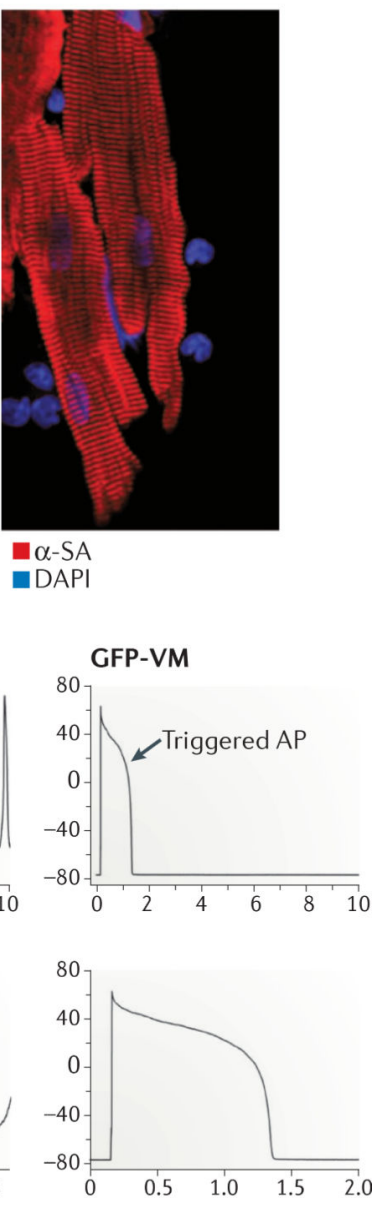

Figure 5. Somatic reprogramming by TBX18.

a A ventricular cardiomyocyte expressing T-box transcription factor TBX18 (TBX18-VM; middle) has a morphology resembling endogenous sinoatrial node (SAN) myocytes (left), in contrast to the rod shape of adult, non-reprogrammed green fluorescent protein (GFP)expressing ventricular cardiomyocytes (GFP-VMs; right). b $\mid$ Reprogrammed ventricular cardiomyocytes (TBX18-VM; top middle) have spontaneous oscillations, and the action potential (AP) morphology resembles that of endogenous SAN myocytes (top left). Nonreprogrammed ventricular cardiomyocytes (GFP-VM; top right) do not have spontaneous depolarizations and produce APs only in response to electrical stimulation. The bottom panels show AP recordings on a higher-resolution timescale. a-SA, a-smooth muscle actin; DAPI, 4',6-diamidino-2-phenylindole; Em, membrane voltage. Figure from REF 11, Macmillan Publishers Limited. 


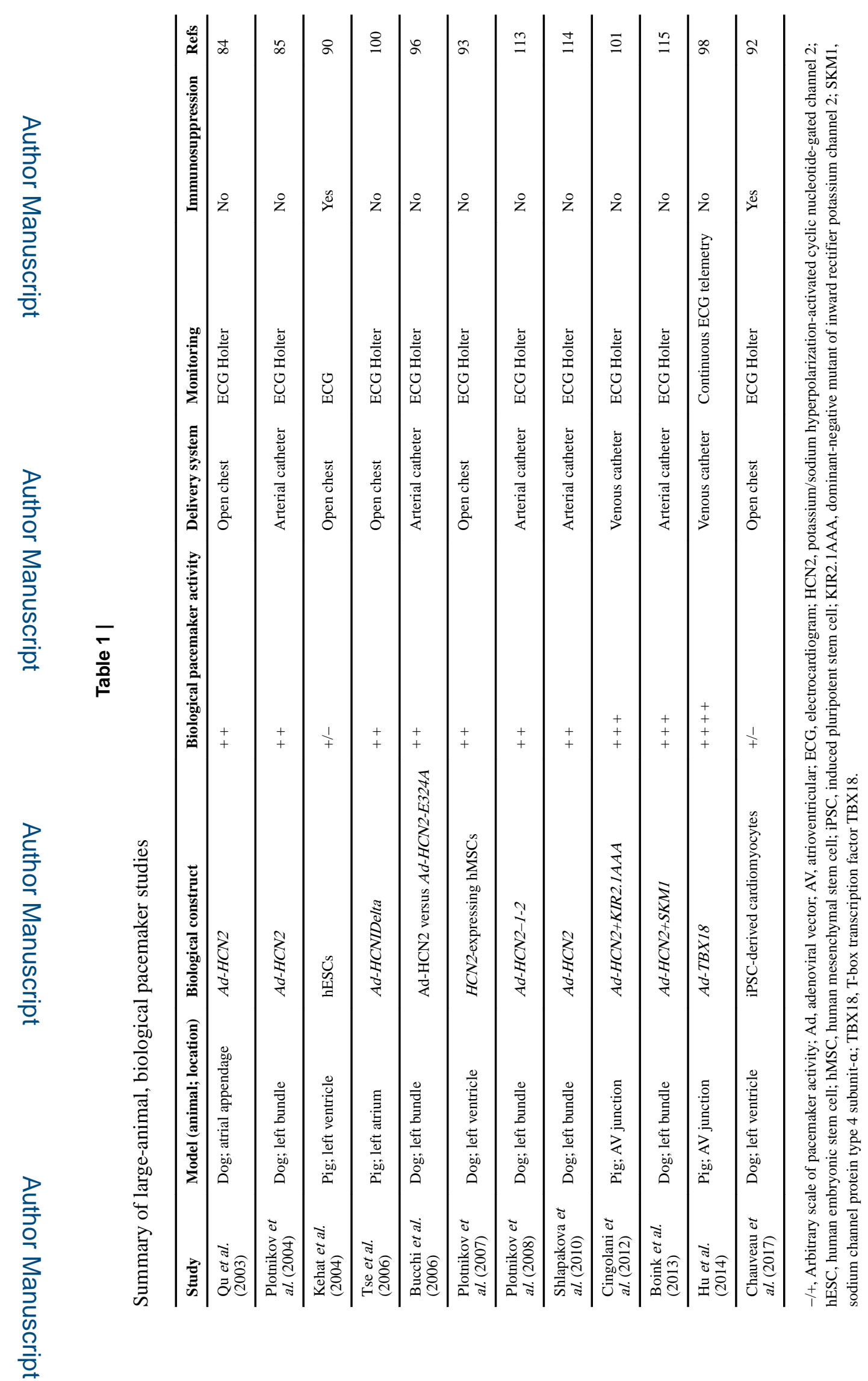

Nat Rev Cardiol. Author manuscript; available in PMC 2018 November 28. 


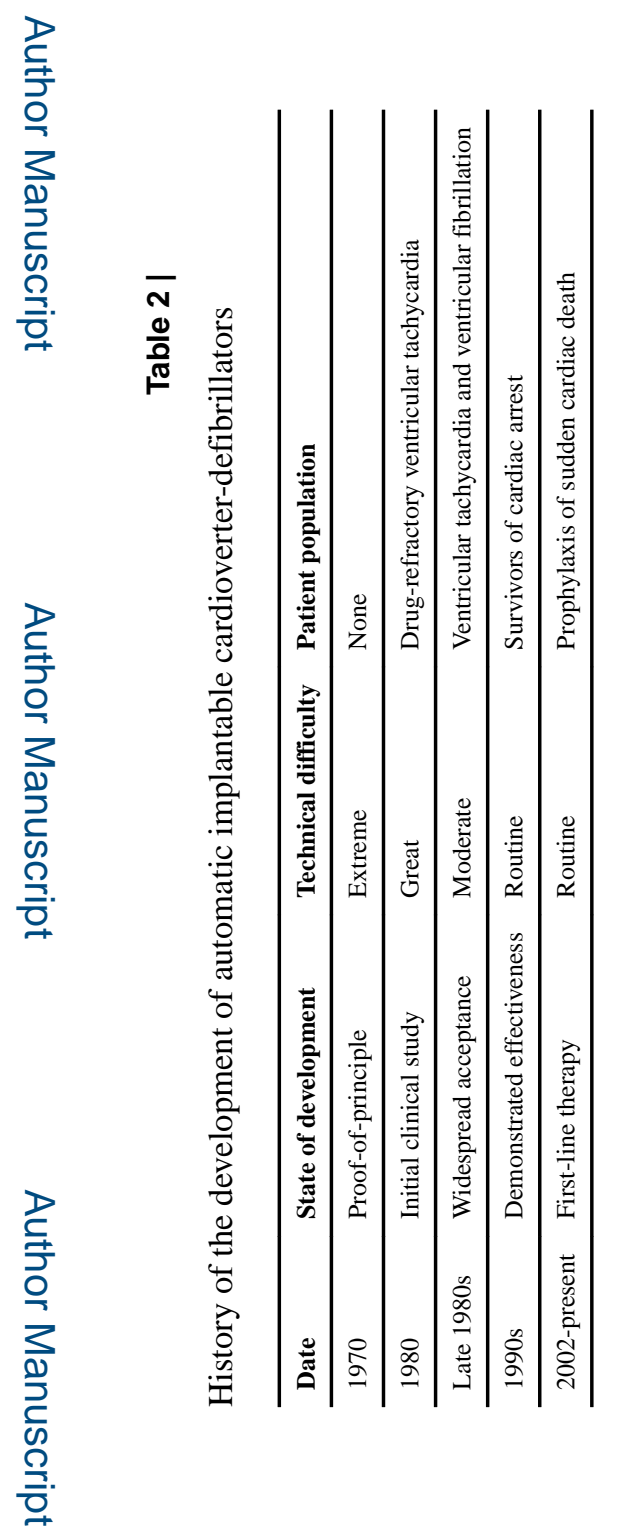

